\title{
Genetic organization, sequence and biochemical characterization of recombinant $\beta$-xylosidase from Thermoanaerobacterium saccharolyticum strain B6A-RI
}

\author{
YoNG-EOK LEE ${ }^{1 \dagger}$ and J. GREGORY ZEIKUS ${ }^{1,2 *}$ \\ 'Department of Microbiology and Public Health, and ${ }^{2}$ Department of Biochemistry, Michigan State University, \\ East Lansing, MI 48824, USA
}

(Received 6 November 1992; revised 3 February 1993; accepted 18 February 1993)

\begin{abstract}
Endoxylanase $(x y n A)$ and $\beta$-xylosidase $(x y n B)$ genes from Thermoanaerobacterium saccharolyticum were subcloned from a cosmid clone (pXDM1) to generate pXPH3. The nucleotide sequence of a PstI-HindIII fragment in pXPH3 that contained $x y n B$ revealed an open reading frame (ORF) of 1500 bp encoding a $55 \mathrm{kDa}$ protein. Another open reading frame (ORF1) of unknown function was found 21 bp downstream from the first stop codon of $x y n B$. $x y n B, O R F 1$ and $x y n A$ had the same direction of transcription. $x y n B$ from $T$. saccharolyticum strain B6A-RI exhibited $45 \%$ amino acid similarity, with $18 \%$ amino acid identity to $x y n A$ of $T$. saccharolyticum strain B6A-RI, and $61 \%$ similarity and $37 \%$ identity with the $\beta$-xylosidase gene from Caldocellum saccharolyticum. Recombinant $\beta$-xylosidase was purified from $E$. coli (pXPH3) cells. The enzyme was a monomer with a molecular mass of $55 \mathrm{kDa}$. The specific activity and $\mathrm{pH}$ and temperature optima for hydrolysis of $p$-nitrophenyl- $\beta$-Dxylopyranoside (pNPX) were $5.53 \mathrm{U} \mathrm{mg}^{-1}, 5.5$ and $70{ }^{\circ} \mathrm{C}$, respectively. The $\beta$-xylosidase was stable at $65{ }^{\circ} \mathrm{C}$, but lost activity at $85^{\circ} \mathrm{C}$. The purified enzyme had hydrolytic activity towards xylopentose, xylotriose, xylobiose and pNPX, but had no activity toward xylan.
\end{abstract}

\section{Introduction}

Xylan is the second most abundant renewable polysaccharide in nature and is comprised of a $\beta$-1,4-linked D-xylose polymer with arabinofuranose, glucuronic acid, methylglucuronic acid and acetyl side-groups (Whistler \& Richards, 1970). Complete breakdown of xylan requires the action of several hydrolytic enzymes of which endoxylanase (EC 3.2.1.8) and $\beta$-xylosidase (EC 3.2.1.37) are the most important (Biely, 1985). Endoxylanase randomly cleaves the $\beta-1,4$ bonds in the xylan backbone to yield oligosaccharides, xylobiose and xylose. The resulting xylo-oligosaccharides are attacked by $\beta$-xylosidase at the non-reducing end (Wong et al., 1988).

*Author for correspondence. Tel. (517) 353 4674; fax (517) 353 9334.

$\dagger$ Present address: Division of Chemistry and Chemical Engineering, California Institute of Technology, Pasadena, CA 91125, USA.

The nucleotide sequence data reported in this paper have been submitted to GenBank and have been assigned the accession number M97883.
Microbial $\beta$-xylosidases occur in both bacteria and fungi, with the latter group being the most studied. Relatively little work has been done on $\beta$-xylosidases from thermophilic bacteria (Bachmann \& McCarthy, 1989; Hudson et al., 1991; Nanmori et al., 1990; Shao \& Wiegel, 1992). To date, only $\beta$-xylosidase genes from Bacillus pumilus (Panbangred et al., 1984; Xu et al., 1991), Bacillus polymixa (Sandhu \& Kennedy, 1984), Bacillus subtilis (Bernier et al., 1983), Butyrivibrio fibrisolvens (Sewell et al., 1989), and Caldocellum saccharolyticum (Luthi et al., 1990) have been cloned into Escherichia coli.

Thermoanaerobacterium saccharolyticum strain B6ARI, a thermophilic anaerobic bacterium isolated from Yellowstone National Park, grows actively on xylan as a sole carbon source and does not have cellulase activity (Lee et al., 1993a). In this organism the degradation of xylan to xylo-oligosaccharides is catalysed by secreted or cell-bound endoxylanases followed by hydrolysis to xylose by intracellular $\beta$-xylosidase. The enzymes are coregulated; their production is induced by xylan or xylose but not glucose (Lee et al., 1993b).

To isolate genes encoding for xylanolytic enzymes a library of $T$. saccharolyticum strain B6A-RI chromo- 
(a)

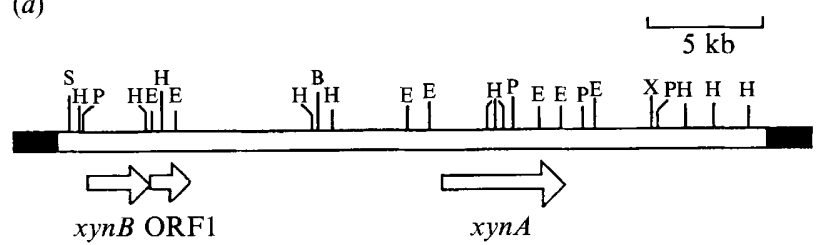

(b)

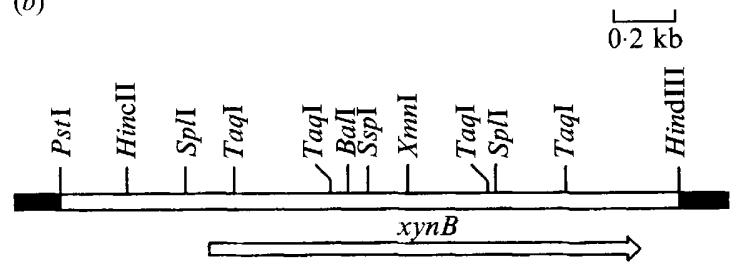

Fig. 1. (a) Physical map of cosmid clone pXDM1 which contains the $28 \mathrm{~kb}$ chromosomal DNA of $T$. saccharolyticum strain B6A-RI expressing the endoxylanase $(x y n A)$ and $\beta$-xylosidase $(x y n B)$ genes. The open area denotes the $28 \mathrm{~kb}$ insert and the closed area represents the pHC79. The DNA was cut at various restriction sites (B, BamHI; E, EcoRI; H, HindIII; P, PstI; S, SaII; X, XbaI). Arrows indicate the location and transcriptional orientation of the genes. (b) Physical and genetic map of the deletion plasmid $\mathrm{pXPH} 3$ containing the $\beta$-xylosidase (xynB) from $T$. saccharolyticum strain B6A-RI. The location and transcriptional orientation of $x y n B$ is indicated by the arrow. The shaded area represents pUC18.

somal DNA was constructed in the cosmid vector pHC79. One cosmid clone, pZXA1, which has a $36 \mathrm{~kb}$ DNA insertion was found to encode both endoxylanase and $\beta$-xylosidase activities. The endoxylanase $(x y n A)$ and $\beta$-xylosidase $(x y n B)$ genes were closely linked within $20 \mathrm{~kb}$ on the chromosome and $x y n A$ has been subcloned and its complete nucleotide sequence determined (Y.-E. Lee, S. E. Lowe \& J. G. Zeikus, unpublished data). The present report describes the complete nucleotide sequence of the $x y n B$ gene, its genetic organization with respect to xylanase $\mathrm{A}(x y n A)$ and the biochemical properties of the $T$. saccharolyticum strain B6A-RI $\beta$-xylosidase expressed in $E$. coli.

\section{Methods}

Bacterial strains and vectors. $T$. saccharolyticum strain B6A-RI was isolated from Yellowstone National Park as described previously (Lee et al., 1993a). Escherichia coli DH5 $\alpha \quad\left(\mathrm{F}^{-} \phi 80 \mathrm{~d} l a c \mathrm{Z} \Delta \mathrm{M} 15\right.$ $\Delta\left[\right.$ lacZYA ${ }^{-}$argF]U169 deoR recAl endAI hsdR17 $\left[\mathrm{r}_{\mathrm{K}}{ }^{-}, \mathrm{m}_{\mathrm{K}}{ }^{+}\right] \operatorname{supE} 441^{-}$ thi-1 gyrA96 relAl) was used as the subcloning host (BRL Life Technologies). Cosmid vector pHC79 (BRL) was used for the construction of a genomic library and plasmid pUC18 (BRL) was used for subcloning.
Chemicals, media and culture conditions. All chemicals were of the highest purity available. Xylose, xylobiose, pNPX, and nitrophenyl derivatives of sugars were purchased from Sigma. Xylotriose and xylopentose were kindly given by Dr P. Reilly at Iowa State University. Restriction enzymes, T4 DNA ligase and calf intestinal alkaline phosphatase were from BRL or Boehringer Mannheim Biochemicals. T. saccharolyticum strain B6A-RI was grown in TYE medium (Zeikus et al., 1980) containing $0.5 \%$ xylose at $60^{\circ} \mathrm{C}$. LB medium ( $10 \mathrm{~g}$ Bacto tryptone, $5 \mathrm{~g}$ Bacto yeast extract, $5 \mathrm{~g} \mathrm{NaCl}$ per litre) supplemented with ampicillin $\left(50 \mu \mathrm{g} \mathrm{ml}^{-1}\right)$ was used to grow $E$. coli strains harbouring recombinant plasmids.

DNA preparation and subcloning procedure. Plasmid DNA harboured by $E$. coli cells was prepared from cleared lysates by the procedure described by Clewell (1972). For screening of recombinant DNA in transformants, a rapid method using the alkaline extraction procedure of Birnboim \& Doly (1979) was used. The basic cloning procedure was performed according to Sambrook et al. (1989). The $x y n \mathrm{~B}$ gene from pXDM1 was excised on a $2 \mathrm{~kb}$ Pst I-HindIII fragment, purified by electroelution, using the Elutrap (Schleicher \& Schuell) and cloned into $P_{\text {st } I-H i n d I I I}$ cut $\mathrm{pUC18}$. The resulting recombinant plasmid was named $\mathrm{pXPH} 3$. Transformation of $E$. coli $\mathrm{DH} 5 \alpha$ was performed by the Hanahan method as described by Perbal (1988). The transformed colonies were replica plated onto LB agar medium containing ampicillin (50 $\mu \mathrm{g} \mathrm{ml}^{-3}$ ) and screened on LB agar plates containing the fluorogenic substrate 4-methylumbelliferyl- $\beta$-D-xylopyranoside (Sigma) at a concentration of $10 \mu \mathrm{g} \mathrm{ml}^{-1}$. The plates were incubated overnight at $37^{\circ} \mathrm{C}$, and the plates containing the fluorogenic substrate were transferred to $60{ }^{\circ} \mathrm{C}$ and examined under ultraviolet light. Positive clones were identified by a blue-white fluorescence due to the diffusion of the umbelliferone released by cleavage of the substrate.

DNA sequencing. Double-stranded DNA sequencing was done on both strands by the method of Sanger et al. (1977) using the Sequenase 2.0 reagent kit (United States Biochemical) according to the manufacturer's instructions. Additional sequencing primers were synthesized by the Michigan State University Macromolecular Structure Facility. DNA sequences were analysed using the GENEPRO software package (Hoefer Scientific Instruments) and the University of Wisconsin Genetics Computer Group GCG package (Version 7) (Devereux et al., 1984).

Enzyme assays. The activity of $\beta$-xylosidase was measured using $p$-nitrophenyl- $\beta$-D-xylopyranoside (pNPX) in 50 mm-sodium acetate buffer, $\mathrm{pH} 5 \cdot 5$. The reaction mixture, composed of $1 \mathrm{~mm}-\mathrm{pNPX}$, $50 \mathrm{~mm}$-sodium acetate (pH 5.5), and diluted enzyme in $0.4 \mathrm{ml}$ reaction volume, was incubated at $60^{\circ} \mathrm{C}$ for $10 \mathrm{~min}$. The reaction was stopped by the addition of $0.8 \mathrm{ml} 0.5 \mathrm{M}-\mathrm{Na}_{2} \mathrm{CO}_{3}$ and the nitrophenol released was measured as $A_{410}$. One unit of enzyme was defined as the amount of enzyme which released $1 \mu \mathrm{mol}$ nitrophenol in $1 \mathrm{~min}$. Other nitrophenol derivatives of sugars were also tested as substrates under the same conditions.

Purification of $\beta$-xylosidase. Unless otherwise stated, all purification steps were carried out at room temperature.

(i) Preparation of cell extract. $\beta$-Xylosidase was purified from $E$. coli $\mathrm{DH} 5 \alpha$ harbouring plasmid pXPH3. Cells grown on one litre of LB medium supplemented with ampicillin were suspended in $40 \mathrm{ml} 50 \mathrm{~mm}$ sodium acetate, $\mathrm{pH} 5 \cdot 5$, and disrupted by passage through a French pressure cell (American Instrument Co.) at 20000 p.s.i. (138 MPa). The

Fig. 2. The nucleotide sequence and deduced amino acid sequence of $\beta$-xylosidase $(x y n B)$ from $T$. saccharolyticum strain B6A-RI, and its flanking region. The underlined region denotes the $\mathrm{N}$-terminal amino acids determined from the purified enzyme, and the start sites for the correct reading frame for $x y n B$ and of ORF1 are indicated by arrows. The putative ribosomal binding site (SD) is labelled with a solid line above the nucleotide sequence. 
1 CTGCAGTATTTGAGAATGGCAACACATCAAGGATAATACCTGCTGTAGAAGCATTGGTATATCCATATGTTGTAGGATATACTGACTTTGTAAGTGAAGA

101 TGGTGTGTTTGGTGAGCTTATAAAAGCCTTAAAGAGCATGTAATGACGATCATGAAGCCTGGTATATGCATAGATGAAGTATCTGECGGTIGGAAACTT

201 TCGTCAACCAGCAAGAATACATGGAATAGCAAAATTTTCTTGTGTCAATATGTGATAAAAGATGTGCTAAATATAGATTTTGGAGAAAAAGAGGCGAAT

301 GGGACAAAGTACATGCCACATGGCAACAGGTGTCTTGCAGTGAAGATTGTGCTACAGATCAGGTAAACAGCGATACAGGTACGCCAAGAGGAAGCCGCTT

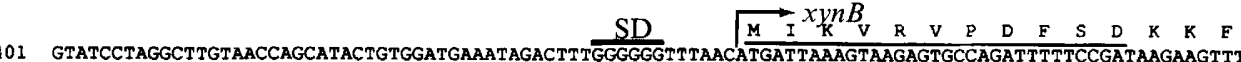

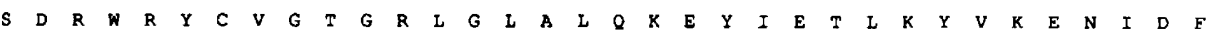

501 CTGATAGATGGAGATATTGTGTCGGAACAGGCAGACTTGGCCTTGCGCTTCAAAAGGATACATCGAGACATTAAAATATGTGAAAGAAAATATAGACTT

$\begin{array}{llllllllllllllllllllllllllllllllllll}K & Y & I & R & G & H & G & \text { L } & \text { L } & C & \text { C } & \text { D } & \text { V } & G & \text { I } & \text { Y } & R & E & D & V & V & G & D & E & V & K & P & F & Y & N & F & T & Y\end{array}$

601 AAGTATATAAGAGGACATGGCCTTTTGTGTGACGATGTAGGCATATACAGAGAAGATGTGGTAGGAGATGAGGTAAAGCCTTTTTACAATTTTACCTAT

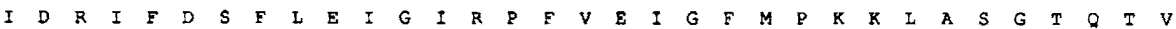

701 ATTGACAGGATTTTGACTCATTTTTAGAAATCGGAATAAGGCCATTTGTGGAAATCGGATTTATGCCTAAAAAATTAGCATCTGGTACACAGACAGTAT

$\begin{array}{lllllllllllllllllllllllllllllllllllll} & F & Y & W & E & G & N & V & T & P & P & K & D & Y & E & K & W & S & D & I & V & K & A & V & L & H & H & F & I & S & R & Y & G & I & E\end{array}$

801 TTTATTGGGAGGGGATGTCACTCCTCCChAGGATTATGAAAAGTGGAGCGATCTTGTCAAAGCGGTTTTGCATCACTTTATTTCTCGATATGGGATTGA

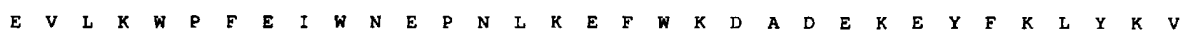

901 AGAAGTCTTGAAGTGGCCATTTGAGATATGGAATGAACCAAACTTAAAAGAGTTTTGGAAAGATGCTGATGAGAAAGAATATTTTAAGCTGTACAAGGTT

\begin{tabular}{lllllllllllllllllllllllllllllllllll}
\hline & A & $K$ & $A$ & $I$ & $K$ & $E$ & $V$ & $N$ & $E$ & $N$ & $L$ & $K$ & $V$ & $G$ & $G$ & $P$ & $A$ & $I$ & $C$ & $G$ & $G$ & $A$ & $D$ & $Y$ & W & $I$ & $E$ & $D$ & $F$ & $L$ & $N$ & $F$
\end{tabular}

1001 ACTGCAAAGGCTATAAAGGAAGTAAATGAAAATTTGAAGGTAGGAGGCCTGCTATATGCGGTGGTGCTGACTACTGGATAGAAGATTTTTTGAATTTCT

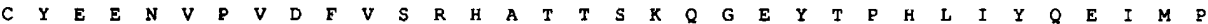
1101 GCTATGAAGAAAATGTTCCTGTAGATTTTGTATCGCGACACGCTACCACATCTAAGCAAGGTGAATATACGCCACATCTCATATACCAGGAGATTATGCC

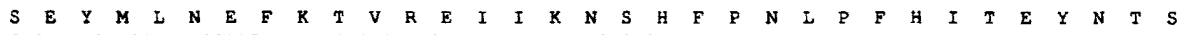
1201 ATCTGAATACATGCTAAACGAATTTAAAACAGTGAGAGAGATCATAAAAAACTCACATTTTCCGAACCTTCCGTTTCATATAACTGAGTACAATACTTCA

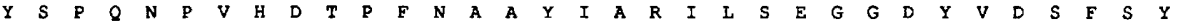
1301 TATAGTCCTCAAAATCCTGTACACGATACGCCATTTAATGCTGCCTATATTGCCAGGATTTTAAGCGAAGGCGGAGATTATGTTGATTCATTTTCTTACT

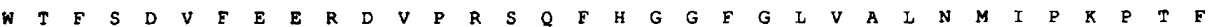
1401 GGACGTTTAGCGACGTTTTCGAAGAAAGAGATGTGCCGCGATCCCAATTCCATGGAGGATTTGGACTTGTGGCATTGAATATGATACCAAAGCCTACCTT

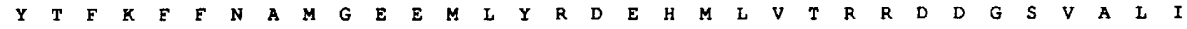

1501 TTACACATTTAAATTCTTTAATGCTATGGGAGAGGAAATGCTTTATAGAGATGAGCACATGCTTGTGACGAGGAGNGRTGATGGCTCTGTTGCACTCATA

$\begin{array}{lllllllllllllllllllllllllllllllllll}A & W & N & E & V & M & D & K & T & E & N & P & D & E & D & Y & E & V & E & I & P & V & R & F & R & D & V & F & I & K & R & Q & L\end{array}$

1601 GCTTGGAATGAAGTTATGGATAAGACTGAAAATCCAGATGAAGATTATGAAGTCGAGATACCAGTTAGATTCAGAGATGTGTTTATTAAAAGACAATTGA

$\begin{array}{llllllllllllllllllllllllllllllllllll}I & D & E & E & \text { H } & G & N & P & W & G & T & W & I & H & M & G & R & P & R & Y & P & S & K & E & Q & V & N & T & L & R & E & V & A & K\end{array}$

1701 TTGATGAAGAACATGGCAATCCATGGGGAACGTGGATACACATGGGAAGGCCGAGTATCCTAGCAAAGAACAGGTAAATACATTGAGAGAAGTTGCAAA

$\begin{array}{lllllllllllllllllllllllllllllllllll}P & E & I & M & T & S & Q & P & V & A & N & D & G & Y & L & N & L & K & F & K & L & G & K & N & A & V & V & L & Y & E & L & T & E\end{array}$ 1801 GCCAGAGATTATGACAAGTCAGCCTGTTGCGAATGACGGATACTTAAATCTAAAGTTTAAATTAGGTAAAAATGCAGTTGTATTGTATGAATTGACTGAG

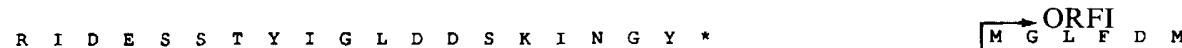

1901 AGAATTGATGAATCAAGCACATATATAGGACTTGATGATAGCAAGATAAATGGATATTGATGCACATTAGGAGGGATTGATATGGGACTTTTTGACATGC

$\begin{array}{lllllllllllllllllllllllllllllllllllll}P & L & Q & K & \text { L } & R & E & Y & T & G & T & N & P & C & P & E & D & F & D & E & Y & W & D & R & A & L & D & E & M & R & S & V & D & P\end{array}$ 2001 CACTGCAAAAGCTJAGAGAATACACTGGTACAAATCCATGCCCTGAAGATTTCGATGAGTATTGGGATAGGGCTTTAGATGAGATGAGGTCAGTTGATCC

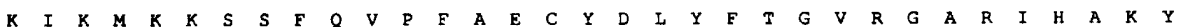
2101 CAAAATTAAAATGAAAAAAAGTAGCTTTCAAGTGCCTSTTGCAGAGTGCTACGATTTGTACTTTACAGGTGTTCGTGGTGCCAGAATTCATGCAAAGTAT

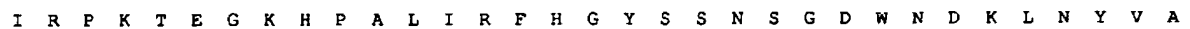

2201 ATAAGACCTAAGACAGAAGGGAAACATCCAGCGTTGATAAGATTTCATGGATATTCGTCAAATTCAGGCGCTGGAACGACAAATTAAATTACGTAGCGG

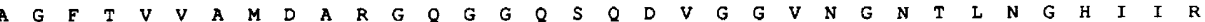
2301 CAGGCTTTACCGTTGTGGCTATGGATGCAAGAGGTCAAGGAGGGCAGTCTCAAGATGTTGGCGGTGTAAATGGGAACACTTTAAATGGGCATATTATAAG

$\begin{array}{llllllllllllllllllllllllllllllllllll}G & \text { L } & D & D & D & A & D & N & M & \text { L } & \text { F } & R & \text { H } & \text { I } & \boldsymbol{E} & \text { L } & \text { D } & \text { T } & \text { A } & Q & \text { L } & \text { A } & G & \text { I } & \text { V } & M & \text { N } & M & \text { P } & E & \text { I } & \text { D } & E\end{array}$ 2401 AGGGTTAGACGATGATGCTGACAACATGCTTTTTAGGCATATCTTCTTAGATACTGCCCAGTTGGCTGGAATAGTTATGAATATGCCAGAAATCGATGAA

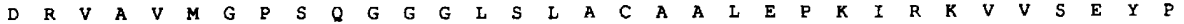
2501 GATAGAGTTGCAGTCATGGGACCTTCTCAAGGTGGAGGTTTGTCATTAGCGTGTGCAGCATTGGAACCCAAGATACGCAAAGTAGTATCAGAGTACCCAT

$\begin{array}{llllllllllllllllllllllllllllllllllll}F & L & S & D & Y & K & R & V & W & D & I & D & L & A & K & N & A & Y & Q & E & I & T & D & Y & F & R & L & F & D & P & R & H & E & R\end{array}$ 2601 TCTTGTCTGATTATAAAAGAGTTIGGGATTTAGACCTTGCGAAAAATGCTTACCAAGAGATTACGGACTATTTTAGGCTTTTTGATCCAAGGCATGAAAG

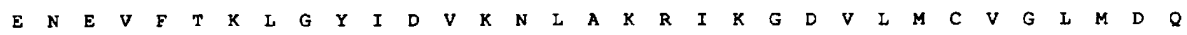
2701 AGAAAATGAGGTGTTTACTAAGCTTGGCTATATAGATGTTAAGAATCTGGCGAAGAGGATAAAAGGGATGTGTTAATGTGCGTTGGGCTTATGGATCAA

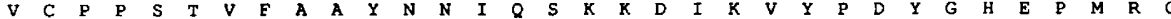
2801 GTATGTCCGCCATCAACTGTCTTTGCAGCCTACAACAACATACAGTCAAAGAAGGATATAAAAGTGTATCCTGATTATGGACATGAGCCTATGAGAGGAT

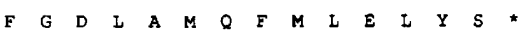

2901 TTGGAGATTTAGCGATGCAGTTIATGTTGGAACTATATTCATAAGGAGATGCAAAGTGCATCTCTTAACTGTATTCTTTATTAATTTTTATATTCGCTT

3001 ACGTTACGTTTAAGCCTGTGTATTTTTTAAAACACGATGAAAAATAATTTGGGTCTTGTATGCCTACAGACTTGGCGATTTCAAATGACTTCATGTTTTI

3101 TTCTTTAATAAGGCTTATGGCTTATGGCTTTTTCCATTCGCTTATTTGTCAGGTATTCTATGAAGTTTATGCCTGTCTCCTTTTTGAATGTTGG 3194 
supernatant obtained by centrifugation $(12000 \mathrm{~g}, 20 \mathrm{~min})$ was used as the crude enzyme preparation.

(ii) Heat treatment. The extract of $E$. coli was heat-treated at $75{ }^{\circ} \mathrm{C}$ for $15 \mathrm{~min}$ in a water bath with shaking, and then chilled on ice. The denatured proteins were removed by centrifugation at $12000 \mathrm{~g}$ for $20 \mathrm{~min}$.

(iii) Anion exchange column chromatography. The supernatant from the heat treatment step was loaded onto a column $(2.5 \mathrm{~cm} \times 18 \mathrm{~cm})$ of Q-Sepharose (Pharmacia) equilibrated with $50 \mathrm{~mm}$-sodium acetate buffer ( $\mathrm{pH} 5.5)$. The enzyme was eluted with a linear gradient $(0-1 \cdot 0 \mathrm{M})$ of sodium chloride in a total volume of $500 \mathrm{ml}$. The active fractions were pooled and concentrated by ultrafiltration with a YM 30 membrane (Amicon)

(iv) Gel filtration chromatography. The concentrated sample was further purified using a Waters FPLC system with a Superose-12 column (Pharmacia) equilibrated with $50 \mathrm{~mm}$-sodium acetate buffer (pH 5.5) containing 50 mM-sodium chloride.

$N$-terminal amino acid sequence determination of $\beta$-xylosidase. The protein was prepared by washing the purified $\beta$-xylosidase five times with double-distilled water using a Centricon-30 (Amicon) filtration device to remove contaminating salts and buffer from the solution. The samples were hydrolysed in vacuo at $110^{\circ} \mathrm{C}$ for $24 \mathrm{~h}$ using $5.7 \mathrm{M}-\mathrm{HCl}$. Amino acid composition analysis was done with a Pico-Tag amino acid analyser (Waters Associates). The $\mathrm{N}$-terminal amino acid sequence was identified by a protein sequencer model 477A (Applied Biosystems) with an on-line phenylthiohydantoin analyser (Applied Biosystems) in the Macromolecular Structure Facility, Department of Biochemistry, Michigan State University.

Protein measurement and PAGE. Protein concentration was estimated by the method of Bradford (1976) using Protein assay reagent from Bio-Rad with BSA (Sigma) as a standard. SDS-PAGE was done as described by Laemmli (1970) using a $12 \%(\mathrm{w} / \mathrm{v})$ polyacrylamide gel. Protein bands were visualized by Coomassie Brilliant Blue R250 staining. The molecular mass of the denatured protein was estimated by SDS-PAGE with low-range molecular mass standards (Bio-Rad) including phosphorylase (97 kDa), BSA (66 kDa), ovalbumin (43 kDa), carbonic anhydrase $(31 \mathrm{kDa})$, soybean trypsin inhibitor $(21.5 \mathrm{kDa})$ and lysozyme $(14 \cdot 4 \mathrm{kDa})$.

Analysis of products of xylan hydrolysis. The xylan and xylooligosaccharides were dissolved in $50 \mathrm{~mm}$-sodium acetate buffer (pH 5.5) and incubated at $60^{\circ} \mathrm{C}$ with approximately $1 \mathrm{U}$ purified enzyme. Samples were withdrawn periodically and the hydrolysis products were analysed by Whatman HP-K high performance silica gel plates $(10 \times 10 \mathrm{~cm})$ using butanol/acetic acid/distilled water $(2: 1: 1$, by vol.), and were visualized using an orcinol spray reagent $(100 \mathrm{mg}$ orcinol in $100 \mathrm{ml} 20 \%$ sulphuric acid in methanol).

\section{Results}

\section{Subcloning and DNA sequencing}

The cosmid clone, pZXA1, with a $36 \mathrm{~kb}$ DNA insert encoding for both endoxylanase and $\beta$-xylosidase activities, was unstable and after several transfers a stable deletion mutant (pXDM1) which retained activity was selected. This cosmid clone contained a $28 \mathrm{~kb}$ insert of $T$. saccharolyticum strain B6A-RI chromosomal DNA which carried the endoxylanase $(x y n A)$ and $\beta$-xylosidase $(x y n B)$ genes (Fig. $1 a$ ). The complete nucleotide sequence of $x y n A$ and its flanking regions had been determined previously and have been deposited with GenBank and assigned the accession number M97882. A $2 \mathrm{~kb}$ Pst IHindIII fragment containing $x y n B$ was subcloned from pXDM1 into pUC18 to produce pXPH3. Fig. $1(b)$ shows the physical map of $x y n B$.

The nucleotide sequence of the $\beta$-xylosidase gene was determined and is shown in Fig. 2. The sequence, which is consistent with the observed restriction map, revealed an ORF of $1500 \mathrm{bp}$, which corresponded to $x y n B$. The molecular mass of the enzyme deduced from the DNA sequence was $55 \mathrm{kDa}$.

A putative ribosome-binding sequence, 5'-GGGGGG$3^{\prime}$, was observed $7 \mathrm{bp}$ upstream from the initiation codon, ATG. Another ORF (ORF1) of unknown function was found $21 \mathrm{bp}$ downstream from the first stop codon of $x y n B$. Interestingly, $x y n B$, ORF 1 and $x y n A$ all have the same direction of transcription (Fig. 1).

\section{Comparison of $x y n B$ with other genes}

Comparison of the deduced amino acid sequence of the $\beta$-xylosidase gene from $T$. saccharolyticum strain B6A$\mathrm{RI}$ to the endoxylanase gene from the same organism, and $\beta$-xylosidases from Bacillus pumilus IPO (Xu et al., 1991), Butyrivibrio fibrisolvens (Sewell et al., 1989) and Caldocellum saccharolyticum (Luthi et al., 1990) revealed little similarity between the enzymes from the mesophiles (less than $16 \%$ identity) compared to the thermophilic enzymes. The endoxylanase and $\beta$-xylosidase from $T$. saccharolyticum strain B6A-RI exhibited $45 \%$ amino acid similarity and had $18 \%$ amino acid identity. Comparison of the $\beta$-xylosidase gene from $T$. saccharolyticum strain B6A-RI with GenBank and EMBL sequence libraries identified the $\beta$-xylosidase gene from Caldocellum saccharolyticum as being most similar, with $61 \%$ similarity and $37 \%$ identity. Using the PILEUP program from the GCG package (University of Wisconsin), significant regions of homology were found between $\beta$-xylosidase A from $C$. saccharolyticum and endoxylanase from $T$. saccharolyticum strain B6A-RI, and between $\beta$-xylosidase B from $C$. saccharolyticum and $\beta$-xylosidase from $T$. saccharolyticum strain B6A-RI (Fig. 3). The translated sequence of $x y_{n} B$ did not share a strong identity with other endoxylanases. No proteins were identified which showed a high amino acid similarity to the putative protein encoded by ORF1 of $T$. saccharolyticum strain B6A-RI.

\section{Purification and characterization of recombinant $\beta$-xylosidase}

Recombinant $\beta$-xylosidase was purified from $E$. coli (pXPH3) cells to determine its physicochemical properties. A summary of the purification procedure is shown in Table 1. Heat treatment was a particularly effective 


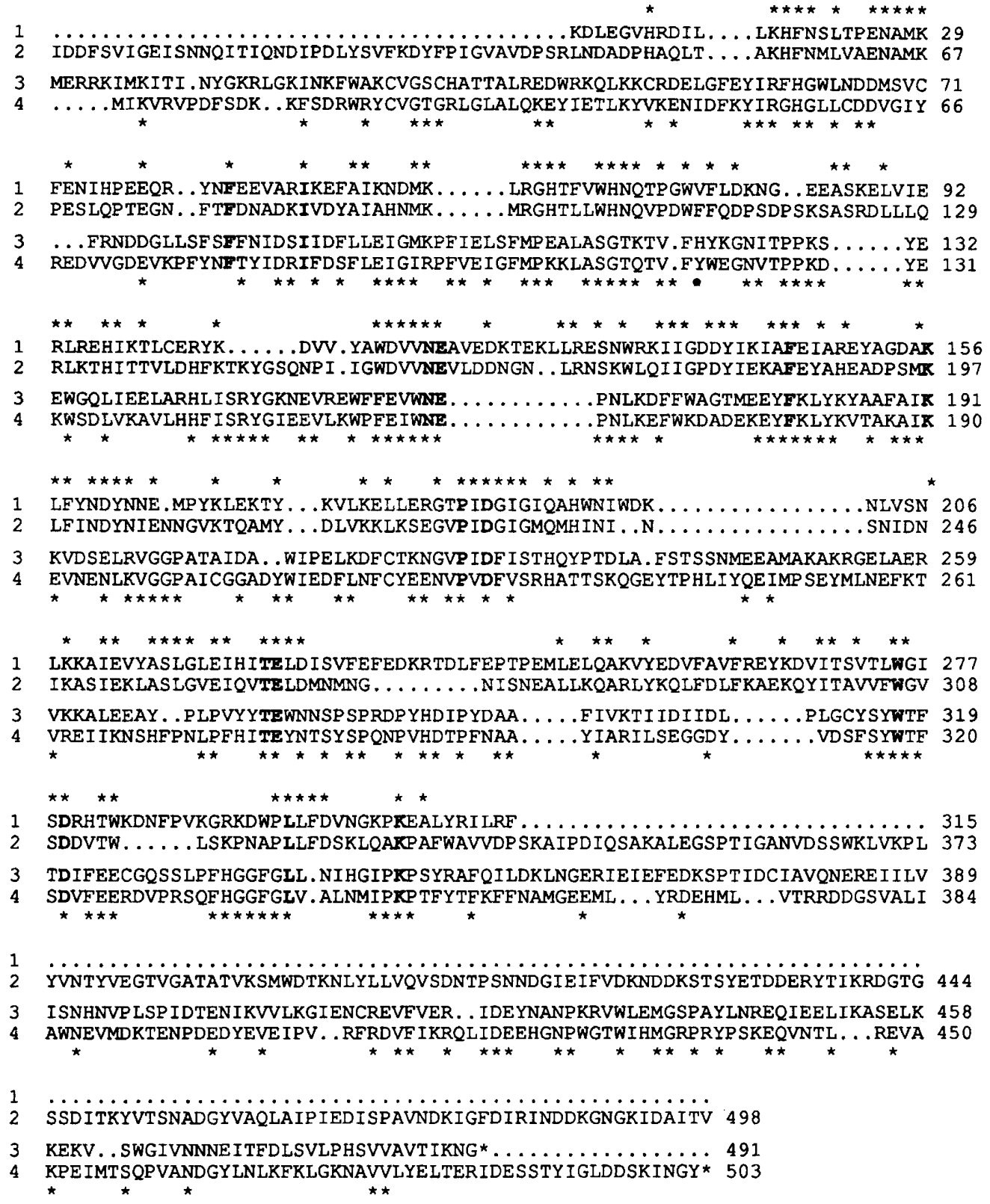

Fig. 3. Deduced amino acid sequence alignment of (1) $\beta$-xylosidase A from Caldocellum saccharolyticum, (2) endoxylanase from $T$. saccharolyticum strain B6A-RI, (3) $\beta$-xylosidase B from $C$. saccharolyticum, (4) $\beta$-xylosidase from $T$. saccharolyticum strain B6A-RI. The asterisks denote conserved amino acids between the two sequences of greatest homology and amino acids in bold are common to all four sequences.

step, resulting in a five-fold purification and $81 \%$ yield. SDS-PAGE analysis (Fig. 4) revealed that the enzyme had an approximate molecular mass of $55 \mathrm{kDa}$. This is identical to the value $(55 \mathrm{kDa})$ calculated from the deduced amino acid sequence. The molecular mass of the recombinant enzyme was estimated at $60 \mathrm{kDa}$ by gel filtration, indicating that this enzyme is monomeric. The $\mathrm{N}$-terminal amino acid sequence of the recombinant $\beta$ xylosidase was Met-Ile-Lys-Val-Arg-Val-Pro-Asp-PheSer-Asp. This was identical to the N-terminal amino acid sequence deduced from the DNA sequence (Fig. 2).
The $\mathrm{pH}$ optimum for hydrolysis of pNPX was about $5 \cdot 5$, with the enzyme showing high activity from $\mathrm{pH} 5.0$ to 6.6 (Fig. $5 a$ ). The optimum temperature for hydrolase activity was $70^{\circ} \mathrm{C}$, with activity decreasing rapidly at higher temperatures (Fig. $5 b$ ). To examine the thermostability of the enzyme, $\beta$-xylosidase was incubated at various temperatures for up to $60 \mathrm{~min}$, and the residual activities were assayed and compared with the untreated sample. $\beta$-Xylosidase was stable at $65^{\circ} \mathrm{C}$, but lost activity at $85^{\circ} \mathrm{C}$. The half-life of the enzyme at $75^{\circ} \mathrm{C}$ was $55 \mathrm{~min}$ (data not shown). 
Table 1. Summary of purification of $\beta$-xylosidase from E. coli $(p X P H 3)$

\begin{tabular}{lccccc}
\hline \hline & $\begin{array}{c}\text { Total } \\
\text { activity } \\
\text { Purification }\end{array}$ & $\begin{array}{c}\text { Total } \\
\text { protein } \\
(\mathrm{mg})\end{array}$ & $\begin{array}{c}\text { Specific } \\
\text { activity } \\
\left(\mathrm{U} \mathrm{mg}^{-1}\right)\end{array}$ & $\begin{array}{c}\text { Purification } \\
(- \text {-fold })\end{array}$ & $\begin{array}{c}\text { Yield } \\
(\%)\end{array}$ \\
\hline Cell-free extract & 165 & 391 & 0.422 & $1 \cdot 0$ & 100 \\
Heat treatment & 134 & 67 & 2.6 & $4 \cdot 7$ & $81 \cdot 2$ \\
Q-Serpharose & 101 & 21 & $4 \cdot 81$ & $11 \cdot 4$ & $61 \cdot 2$ \\
Gel filtration & 83 & 15 & $5 \cdot 53$ & $13 \cdot 1$ & $50 \cdot 3$ \\
\hline
\end{tabular}

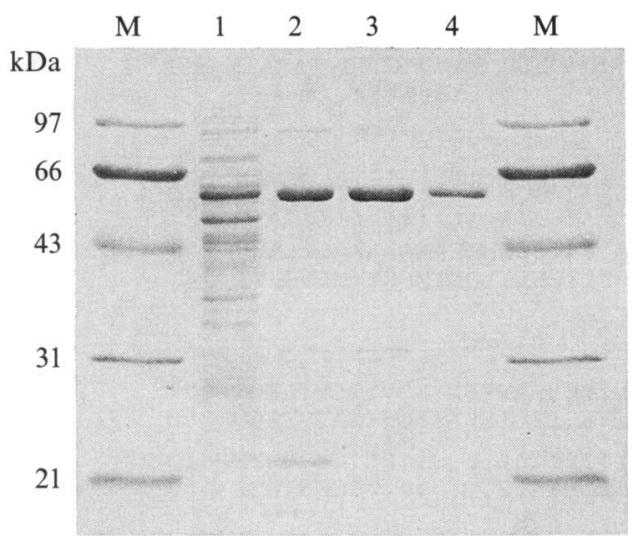

Fig. 4. SDS-PAGE analysis of the purification of recombinant $\beta$ xylosidase from $E$. coli ( $\mathrm{pXPH3)}$ cells. Lane $\mathrm{M}$, molecular mass markers; lane 1, crude E. coli (pXPH3) extract ( $200 \mu \mathrm{g}$ protein); lane 2 , following heat treatment $(10 \mu \mathrm{g}$ protein); lane 3, after anion exchange chromatography ( $5 \mu \mathrm{g}$ protein) and lane 4 , after gel filtration chromatography ( $3 \mu \mathrm{g}$ protein).

\section{Table 2. Expression and localization of $\beta$-xylosidase}

Cells were harvested from the late exponential phase at an $\mathrm{OD}_{660}$ of 1.30 and 2.20 for $T$. saccharolyticum and $E$. coli, respectively.

\begin{tabular}{lcc}
\hline \hline & \multicolumn{2}{c}{ Specific activity $\left(\mathrm{U} \mathrm{mg}^{-1}\right)$} \\
\cline { 2 - 3 } Organism & Supernatant & Intracellular \\
\hline E. coli (pXPH3) & 0 & $0 \cdot 16$ \\
T. saccharolyticum & 0 & $1 \cdot 26$ \\
strain B6A-RI & & \\
\hline
\end{tabular}

Localization studies revealed that $\beta$-xylosidase was intracellular in both the recombinant organism and $T$. saccharolyticum strain B6A-RI (Table 2). Lower levels of $\beta$-xylosidase were expressed in $E$. coli compared to $T$. saccharolyticum, and in both organisms levels of $\beta$-xylosidase were dependent on growth phase and increased in the stationary phase.

The activity of the purified $\beta$-xylosidase with various para- and ortho-nitrophenyl-glycosidic substrates was tested (Table 3 ). The $\beta$-xylosidase was highly specific, as
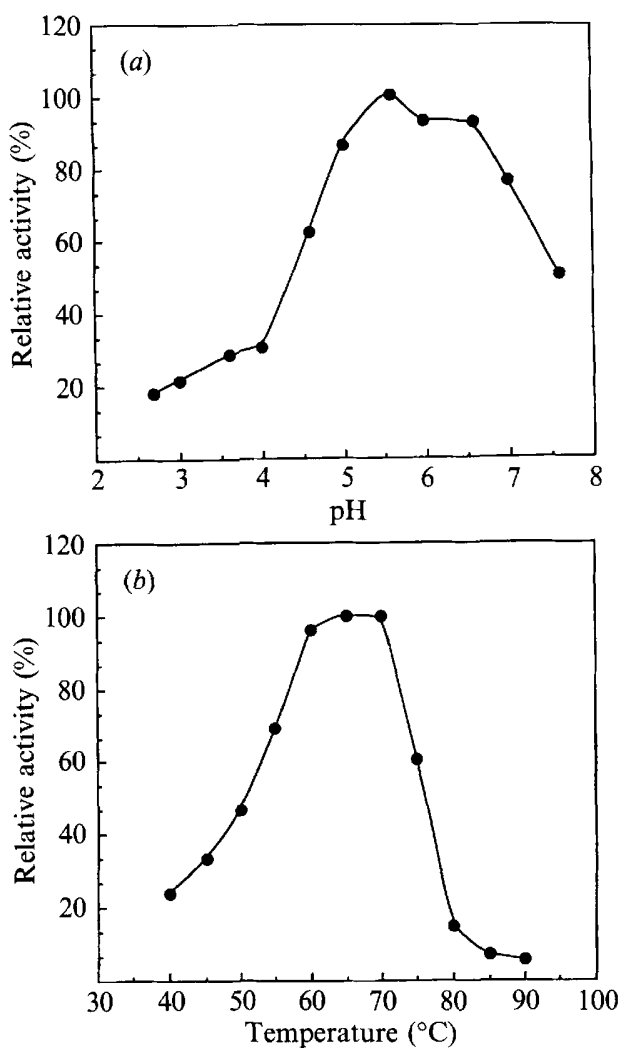

Fig. 5. The $\mathrm{pH}(a)$ and temperature $(b)$ profile of recombinant $\beta$ xylosidase. Citrate/phosphate buffer $(0 \cdot 1 \mathrm{M})$ was used for determination of the $\mathrm{pH}$ optimum, and $50 \mathrm{~mm}$-sodium acetate buffer ( $\mathrm{pH} \mathrm{5.5)}$ for determination of the temperature optimum. The $100 \%$ value represents $44 \mathrm{U}$ and $17 \mathrm{U}$ of $\beta$-xylosidase for $\mathrm{pH}$ and temperature profiles, respectively.

Table 3. Hydrolysis of various nitrophenyl-glycosides by the purified $\beta$-xylosidase

Values are means of three independent experiments.

\begin{tabular}{lc}
\hline Substrate & $\begin{array}{c}\text { Specific activity } \\
\left(\mathrm{U} \mathrm{mg}^{-1}\right)\end{array}$ \\
\hline$p$-Nitrophenyl- $\beta$-D-xylopyranoside & $5 \cdot 529$ \\
$o$-Nitrophenyl- $\beta$-D-xylopyranoside & 4.696 \\
$p$-Nitrophenyl- $\beta$-D-fucopyranoside & 0.045 \\
$p$-Nitrophenyl- $\alpha$-D-glucopyranoside & 0.000 \\
$p$-Nitrophenyl- $\beta$-D-glucopyranoside & 0.141 \\
$p$-Nitrophenyl- $\alpha$-L-arabinofuranoside & 0.073 \\
$o$-Nitrophenyl- $\beta$-D-galactopyranoside & 0.000 \\
$p$-Nitrophenyl- $\beta$-D-lactopyranoside & 0.000 \\
\hline
\end{tabular}

it was active only on $p$-nitrophenyl- $\beta$-D-xylopyranoside and $o$-nitrophenyl- $\beta$-D-xylopyranoside. The low level of activity observed with $p$-nitrophenyl- $\beta$-D-fucopyranoside, $\quad p$-nitrophenyl- $\alpha$-L-arabinofuranoside and $p$ nitrophenyl- $\beta$-D-glucopyranoside may not be significant, and no activity was detected with the other substrates tested. 

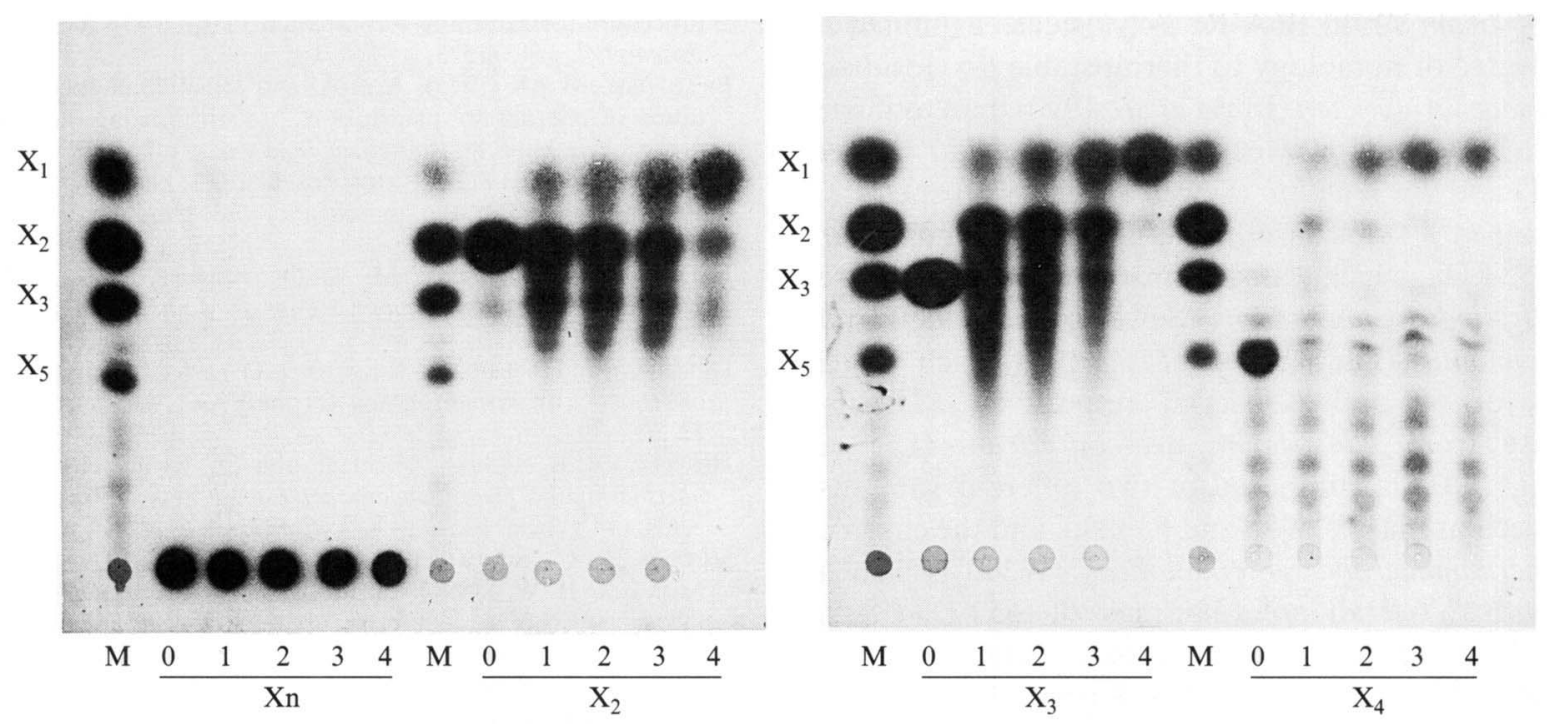

Fig. 6. Time course of hydrolysis of the soluble fraction of oat spelt xylan and xylo-oligosaccharides by the recombinant $\beta$-xylosidase. Oligosaccharides of xylose (xylobiose, xylotriose and xylopentose) and oat spelt xylan were incubated with purified $\beta$-xylosidase and analysed using TLC. Lane $M$, size markers of (vertical scale) xylose $\left(X_{1}\right)$, xylobiose $\left(X_{2}\right)$, xylotriose $\left(X_{3}\right)$ and xylopentose $\left(X_{5}\right)$. For the other lanes, xylan $(X n)$, xylobiose $\left(X_{2}\right)$, xylotriose $\left(X_{3}\right)$ and xylopentose $\left(X_{5}\right)$ were hydrolysed, and samples were taken at time $0(0)$, $15 \mathrm{~min}(1), 30 \mathrm{~min}(2), 1 \mathrm{~h} \mathrm{(3)}$ and $5 \mathrm{~h} \mathrm{(4)}$

Oligosaccharides of xylose (xylobiose, xylotriose and xylopentose) and oat spelt xylan were incubated with purified $\beta$-xylosidase and analysed using TLC (Fig. 6). All of the xylo-oligosaccharides (polymers of two to five xylose residues) were degraded to xylose. Transferase activity was also detected by the appearance of xylotriose during the early stages of hydrolysis of xylobiose. No activity could be detected using oat spelt xylan as the substrate. No $\beta$-xylosidase activity was detected in control extracts from $E$. coli.

\section{Discussion}

The complete nucleotide sequence of the $\beta$-xylosidase gene of $T$. saccharolyticum strain B6A-RI was established, together with its flanking regions. In our other studies, the endoxylanase and $\beta$-xylosidase activity of $T$. saccharolyticum strain B6A-RI have been shown to be under co-ordinate control, induced by xylose or xylan (Lee et al., 1993b), and the endoxylanase gene (xynA) has been cloned and sequenced (Y.-E. Lee, S. E. Lowe \& J. G. Zeikus, unpublished data). In the cloned chromosomal DNA from $T$. saccharolyticum strain B6A-RI, $x y n A$ and $x y n B$ genes were clustered within a $20 \mathrm{~kb}$ region, and had the same transcriptional orientation. The proximity of $x y n B$, ORF 1 and $x y n A$ in the cloned DNA and the uniform direction of transcription of these genes suggests that they may be organized into an operon. This is further substantiated by the finding that no terminator or prominent stem-loop structure was identified in the sequence analysed. However, it remains to be shown that $x y n A$ and $x y n B$ are part of the same operon in $T$. saccharolyticum strain B6A-RI. Studies using RNA, such as Northern blot analysis and primer extension experiments would address this question. Recent studies with Bacteroides ovatus (Whitehead \& Hespell, 1990), Bacillus pumilus (Panbangred et al., 1984), Pseudomonas fluorescens (Kellet et al., 1990) and Caldocellum saccharolyticum (Luthi et al., 1990) have reported the clustering of genes involved in hemicellulose degradation in these organisms.

Confirmation that the cloned $x y n B$ is from the $T$. saccharolyticum strain B6A-RI chromosomal DNA was obtained by Southern blot analysis. A single Pst I and $X b a \mathrm{I}$ fragment hybridized to the $\beta$-xylosidase probe, suggesting that there is only one chromosomal copy of the cloned gene. However, the possibility that $T$. saccharolyticum strain B6A-RI has more than one $\beta$ xylosidase cannot be ruled out, since multiple $\beta$ xylosidases have been reported in Bacillus pumilus (Panbangred et al., 1984) and C. saccharolyticum (Luthi et al., 1990).

Localization studies of the cloned $\beta$-xylosidase revealed that the enzyme was located within the $E$. coli cell. This is consistent with the observation that most of the $\beta$-xylosidase activity from $T$. saccharolyticum strain B6A-RI was intracellular, as has been found for the closely related thermophilic anaerobes Thermoanaerobacter strain B6A (Hespell, 1992) (now Thermoanaerobacterium saccharolyticum strain B6A) and Thermoanaerobacter ethanolicus JW200 (Shao \& Wiegel, 1992). The deduced amino acid sequence of thermostable $T$. 
saccharolyticum strain B6A-RI $\beta$-xylosidase exhibited a higher degree of homology to thermostable $\beta$-xylosidase from C. saccharolyticum (Luthi et al., 1990) than to those of less thermostable $\beta$-xylosidases from Bacillus (Xu et al., 1991) and Butyrivibrio (Sewell et al., 1989) species.

The cloned $\beta$-xylosidase had a monomeric molecular mass of $55 \mathrm{kDa}$, which was similar to that of $\beta$-xylosidase from Butyrivibrio fibrisolvens (Sewell et al., 1989) and Bacillus pumilus (Panbangred et al., 1984) each single subunits of 60 and $62.6 \mathrm{kDa}$, respectively. The $\beta$ xylosidase from Clostridium acetobutyricum (Lee \& Forsberg, 1987) is composed of two different subunits with molecular masses of 85 and $63 \mathrm{kDa}$, and the enzyme from Thermoanaerobacter ethanolicus JW200 is also a dimer, with an overall molecular mass of $165 \mathrm{kDa}$ (Shao $\&$ Wiegel, 1992). Fungal $\beta$-xylosidases have relatively larger subunits of 116 to $118 \mathrm{kDa}$ (Kitpreechavabichi et al., 1986; Matsuo \& Yasui, 1984).

$\beta$-Xylosidase from $T$. saccharolyticum strain B6A-RI and T. ethanolicus JW200 (Shao \& Wiegel, 1992) have the same $\mathrm{pH}$ optimum, although the enzyme from the latter organism was more thermostable. There was no significant similarity between the $\mathrm{N}$-terminal sequences of the $\beta$-xylosidases from these two organisms.

The substrate specificity of $\beta$-xylosidase from $T$. saccharolyticum strain B6A-RI for xylo-oligosaccharides was similar to that of other bacterial $\beta$-xylosidases (Deleyn et al., 1982; Lee \& Forsberg, 1987; Panbangred et al., 1984; Sewell et al., 1989), with the exception of $\beta$ xylosidase from Thermoanaerobacter ethanolicus, which also possessed high arylarabinosidase activity, but had a lower affinity for $p$-nitrophenyl- $\alpha$-L-arabinoside and $p$ nitrophenyl- $\beta$-D-xylopyranoside (Shao \& Wiegel, 1992). Most $\beta$-xylosidases have little or no activity against xylan, and this was also found with $\beta$-xylosidase from $T$. saccharolyticum strain B6A-RI. These enzymes degrade xylo-oligosaccharides to xylose and also have transferase activity, which are considered to be the properties of a $\beta$ xylosidase (Reilly, 1981).

This material is based upon work supported by the Cooperative State Research Service, US Department of Agriculture, under Agreement No. 90-34189-5014. In addition, we would like to thank Sue Lowe for her valuable suggestions in this research and in the preparation and completion of this manuscript.

\section{References}

Bachmann, S. L. \& McCarthy, A. J. (1989). Purification and characterization of a thermostable $\beta$-xylosidase from Thermomonospora fusca. Journal of General Microbiology 135, 293-299.

Bernier, R., JR, Driguez, H. \& Desrochers, M. (1983). Molecular cloning of Bacillus subtilis xylanase gene in Escherichia coli. Gene $\mathbf{2 6}$, $59-65$.

BIELY, P. (1985). Microbial xylanolytic systems. Trends in Biotechnology 3, 286-290.

Birnboim, H. C. \& Doly, J. (1979). A rapid alkaline extraction procedure for screening recombinant plasmid DNA. Nucleic Acids Research 7, 1513-1523.

BradFord, M. M. (1976). A rapid and sensitive method for quantitation of microgram quantities of protein utilizing the principle of protein-dye binding. Analytical Biochemistry 72, 248-254.

Clewell, D. B. (1972). Nature of Col E1 plasmid replication in Escherichia coli in the presence of chloramphenicol. Journal of Bacteriology 110, 667-676.

Deleyn, F., Claeyssens, M. \& De Bruyne, C. K. (1982). $\beta$-DXylosidase from Penicillium wortmanni. Methods in Enzymology 83, 639-644.

DevereuX, J., Haeberli, P. \& Smithies, O. (1984). A comprehensive set of sequence analysis programs for the VAX. Nucleic Acids Research 12, 387-395.

HesPell, R. B. (1992). Fermentation of xylans by Butyrivibrio fibrisolvens and Thermoanaerobacter strain B6A: utilization of uronic acids and xylanolytic activities. Current Microbiology 25, 189-195.

Hudson, R. C., Schofield, L. R., Coolbear, T., Daniel, R. M. \& Morgan, H. W. (1991). Purification and properties of an aryl $\beta$ xylosidase from a cellulolytic extreme thermophile expressed in Escherichia coli. Biochemical Journal 273, 645-650.

Kellet, L. E., Poole, D. M., Ferreira, L. M., Durrant, A. J., Hazlewood, G. P. \& GilberT, H. J. (1990). Xylanase B and an arabinofuranosidase from Pseudomonas fluorescens subsp. cellulosa contain identical cellulose-binding domains and are encoded by adjacent genes. Biochemical Journal 272, 369-376.

KitPreechavanichi, V., Hayashi, M. \& NaGai, S. (1986). Purification and characterization of extracellular $\beta$-xylosidase and $\beta$-glucosidase from Aspergillus fumigatus. Agricultural and Biological Chemistry 50, 1703-1711.

LAEMMLI, U. K. (1970). Cleavage of structural proteins during the assembly of the head of bacteriophage T4. Nature, London 227, 680-685.

LEE, S. F. \& ForsBERG, C. W. (1987). Isolation and some properties of a $\beta$-D-xylosidase from Clostridium acetobutylicum ATCC 824. Applied and Environmental Microbiology 53, 651-654.

LeE, Y.-E., JAIN, M. K., LeE, C., Lowe, S. E. \& ZeIKus, J. G. (1993a). Taxonomic distinction of saccharolytic thermoanaerobes: description of Thermoanaerobium xylanolyticum gen. nov., sp. nov. and Thermoanaerobium saccharolyticum sp. nov. Reclassification of Thermoanaerobium brockii, Clostridium thermosulfurogenes and Clostridium thermohydrosulfuricum E100-69 as Thermoanaerobacter brockii comb. nov., Thermoanaerobacterium thermosulfurigenes comb. nov. and Thermoanaerobacterium thermohydrosulfuricus comb. nov., and transfer of Clostridium thermohydrosulfuricum $39 \mathrm{E}$ to Thermoanaerobacter ethanolicus. International Journal of Systematic Bacteriology 43, 41-51.

LeE, Y.-E., Lowe, S. E. \& ZeIKus, J. G. (1993b). Regulation and characterization of xylanolytic enzymes of Thermoanaerobacterium saccharolyticum strain B6A-RI. Applied and Environmental Microbiology (in the Press).

luthi, E., Love, D. R., Mcanulty, J., Wallace, C., Caughey, P. A., Saul, D. \& Bergquist, P. L. (1990). Cloning, sequence analysis, and expression of genes encoding xylan-degrading enzymes from the thermophile 'Caldocellum saccharolyticum'. Applied and Environmental Microbiology 56, 1017-1024.

Matsuo, M. \& Yasul, T. (1984). Purification and some properties of $\beta$ xylosidase from Emericella nidulans. Agricultural and Biological Chemistry 48, 1853--1860.

Nanmori, T., Watanabe, T., Shinke, R., Kohno, A. \& Kawamura, Y. (1990). Purification and properties of thermostable xylanase and $\beta$-xylosidase produced by a newly isolated Bacillus stearothermophilus strain. Journal of Bacteriology 172, 6669-6672.

Panbangred, W., Kawaguchi, O., Tomita, T., Shinmyo, A. \& OKaDA, H. (1984). Isolation of two $\beta$-xylosidase genes of Bacillus pumilus and comparison of their gene products. European Journal of Biochemistry 138, 267-273.

Perbal, B. (1988). A Practical Guide to Molecular Cloning, 2nd edn. New York: John Wiley \& Sons.

ReILly, P. J. (1981). Xylanase: structure and function. Basic Life Sciences 18, 111-129.

Sambrook, J., Fritsch, E. F. \& Maniatis, T. (1989). Molecular 
Cloning: A Laboratory Manual, 2nd edn. Cold Spring Harbor, NY: Cold Spring Harbor Laboratory Press.

SANDhu, J. S. \& KenNedy, J. F. (1984). Molecular cloning of Bacillus polymixa $1 \rightarrow 4-\beta$-D xylanase EC 3.2.1.8 gene in Escherichia coli. Enzyme and Microbial Technology 6, 271-274.

SANGer, F., Nicklen, S. \& Coulson, A. R. (1977). DNA sequencing with chain-terminating inhibitors. Proceedings of the National Academy of Sciences of the United States of America 74, 5463-5467.

Sewell, G. W., Utt, E. A., Hespell, R. B., Mackenzie, K. F. \& INGRAM, L. O. (1989). Identification of the Butyrivibrio fibrisolvens xylosidase gene $(x y l B)$ coding region and its expression in Escherichia coli. Applied and Environmental Microbiology 55, 306-311.

Shao, W. \& Wiegel, J. (1992). Purification and characterization of a thermostable $\beta$-xylosidase from Thermoanaerobacter ethanolicus. Journal of Bacteriology 174, 5848-5853.

Whistler, R. L. \& Richards, E. L. (1970). Hemicelluloses. In The
Carbohydrates - Chemistry and Biochemistry, 2nd edn, vol 2A, pp. 447-469. Edited by W. Pigman \& D. Horton. New York: Academic Press.

WhiteHEAD, T. R. \& Hespell, R. B. (1990). The genes for three xylandegrading activities from Bacteroides ovatus are clustered in a 3.8kilobase region. Journal of Bacteriology 172, 2408-2412.

WONG, K. K. Y., TAN, L. U. L. \& SAdDLER, J. N. (1988). Multiplicity of $\beta$-1,4-xylanase in micro-organisms: functions and applications. Microbiological Reviews 52, 305-317.

Xu, W.-Z., Shima, Y., Negoro, S. \& Urabe, I. (1991). Sequence and properties of $\beta$-xylosidase from Bacillus pumilus IPO: contradiction of the previous nucleotide sequence. European Journal of Biochemistry 202, 1197-1203.

Zeikus, J. G., Ben-Bassat, A. \& Hegge, P. (1980). Microbiology of methanogenesis in thermal volcanic environments. Journal of Bacteriology 143, 432-440. 